\title{
Risk Factors And Pregnancy Outcomes Among Pregnant Women With Pre-Eclampsia
}

\author{
Rasha Mohamed Essa \& Abeer Abd El Aziz Madian
}

Assistant Prof. of Obstetric \& Gynecological Nursing Dept, Faculty of Nursing, Damanhour University, Egypt. Lecturer of Community health Nursing Dept, Faculty of Nursing, Damanhour University, Egypt.

\begin{abstract}
Background: Pre-eclampsia (PE) is a pregnancy specific disorder and a major cause of both fetal and maternal morbidity and mortality worldwide. The Aim of this study was to identify risk factors and pregnancy outcomes among pregnant women with pre-eclampsia. Research design: An exploratory descriptive design was used. Sample:A purposive of 200 women who were selected randomly. Setting: from labor unit affiliated to Damanhour Medical National Institute. Tools: three tools were used to collect data. The first tool was a structured interview questionnaire. The second tool: assessment of women's knowledge regarding pre-eclampsia and the third tool pregnancy outcome assessment checklist. Results: Premature rupture of membranes was observed among approximately three- quarters of them. More than half of them had caesarean section labor. Fetal distress was observed among about one-third of them and low birth weight (1500-2400 gm) constituted $27.6 \%$ of study subjects. Furthermore, admission to neonatal intensive care unit and oxygen administration were needed for ( $23 \%$ \& $36.8 \%$ ) of study subjects' neonates respectively. Also, positive significant correlations were observed between pre-eclampsia and age, education, residence, parity as well as number of antenatal visit. In addition $69.0 \%$ of study subjects had poor total score. The study concluded that, age, level of education, residence, parity, and antenatal visits were determinants risk factors of pre-eclampsia in which that was significantly associated with maternal and neonatal morbidities as well as increasing cesarean section, LBW, and birth asphyxia. Consequently, it is recommended that teaching programs should be conducted to identify mothers at risk and encourage them for proper antenatal care.
\end{abstract}

\section{Key Words: Pre-Eclampsia, Risk Factors, Maternal Outcomes \& Neonatal Outcomes.}

\section{Introduction}

Pregnancy is a unique, exciting often blissful time in women's life. It highlights the women's amazing creative and nurturing powers while providing bridge to the future. Pregnant women need to be responsible for providing support the health of her future child. The growing fetus depends entirely on its mothers' healthy body for all this needs. Consequently pregnant women must take steps to remain as healthy and well-nourished as they possibly can (Casey, et al., 2015)

Hypertensive disorders of pregnancy remain among the most significant and intriguing unsolved problems in obstetrics. It complicates $5-10 \%$ of all pregnancies and together they form one member of the deadly triad, along with hemorrhage and which contributes greatly to maternal morbidity and mortality. In developed countries about $16 \%$ of maternal deaths are due to hypertensive disorders. This includes: gestational hypertension, pre-eclampsia and eclampsia as well as chronic hypertension and preeclampsia superimposed on chronic hypertension (Costa, et al., 2010)

Pre-eclampsia (PE) is a pregnancy specific disorder commonly defined as hypertension and proteinuria after 20 weeks of gestational age. It occurs in approximately $3-5 \%$ of pregnancies and is still a major cause of both fetal and maternal morbidity and mortality worldwide (Costa, et al., 2009) and several factors are associated with pre-eclampsia but some are not clearly proved. Current theories for the pathogenesis of pre-eclampsia include abnormal placentation, cardiovascular maladaptation to pregnancy, genetic and immune mechanisms, enhanced systemic inflammatory responses, nutritional, hormonal and angiogenic factors (Baker, et al., 2010).

Pre-eclampsia is a multisystem disorder of pregnancy. Alam, (2010) reported that, it is divided into mild and severe forms depending on the amount of elevation of the blood pressure and the degree of proteinuria. In mild type: blood pressure ranges from $140 / 90$ to $160 / 110 \mathrm{mmHg}$; proteinuria < $5 \mathrm{gm} / 24 \mathrm{hrs}$; edema of face, hands and feet are the prominent signs. On the other hand, severe pre-eclampsia is characterized by: blood pressure $>160 / 110 \mathrm{mmHg}$; proteinuria $>5 \mathrm{~g}$ per $24 \mathrm{hrs}$; oliguria $<400 \mathrm{ml}$ in 24 hrs; cerebral or visual disturbances; epigastric pain or more specifically right upper quadrant pain that may indicate liver involvement; pulmonary edema, hepatocellular dysfunction, thrombocytopenia, elevated serum creatinine and microangiopathic hemolysis (Sudha, et al., 2009 \& Rathore, et al., 2010) 
The prevalence of pre-eclampsia varies according to the difference in classifications, definitions and the fact that many estimates are hospital basis (Dekker 2014) Most of the complications, related to preeclampsia are occurring due to maternal negligence or unawareness on the disease and its management. Self-care offers a real potential for improving their health status, and thus to prevent the severe form of pre-eclampsia at a deteriorating health cost. Self-care would be the most effective and appropriate approach to enhance both maternal and fetal well-being, as well as the successful outcome of pregnancy (Laura, et al., 2014)

Pre- eclampsia is confounded by the continued mystery of the etiology and the unpredictable nature of the disease. So, it can be controlled by regulation of diet, relaxation, by avoiding stress, early identification and medication, monitoring blood pressure level, rest, urine testing for the presence of albumin and by making some adjustments in lifestyles. Clearly, the need for education and awareness among these women remains evident (Namitha, et al., 2010). To date, few studies have examined maternal and neonatal complications and outcomes in pre-eclampsia in Egypt.

\section{Significance of study}

Pre-eclampsia complicates around $5 \%$ of pregnancies and hypertensive disorders of pregnancy are responsible for over 60,000 maternal deaths worldwide annually (Kate, et al., 2015) However, the impact of the disease is felt more severely in developing countries, incidence of eclampsia in developing nations varies widely, ranging from 1 case per 100 pregnancies to 1 case per 1700 pregnancies . Rates from African countries such as South Africa, Egypt, Tanzania, and Ethiopia vary from $1.8 \%$ to 7.1 $\%$ ( WHO 2011). Pre-eclampsia needs to be identified as a priority area in reducing maternal mortality in developing countries. So, raising awareness of the need for women to reach antenatal care, emergency care without delay and trained to recognize danger signs during pregnancy are responsibilities of maternity and community health nurses.

\section{Aim of study}

This study was conducted to identify risk factors and pregnancy outcomes among pregnant women with pre-eclampsia.

\section{Research questions}

- What are the association between ages, level of education, residence, parity, antenatal visits , BMI, family income, weeks of gestation and preeclampsia?

- What are pregnancy outcomes among pregnant women with pre-eclampsia?

\author{
Operational definitions \\ Pregnancy outcome include maternal and fetal \\ outcome
}

Maternal outcome involves weeks of gestation, onset of labor, type of delivery, maternal distress, rupture of membranes, as well as duration and complications of labor.

Fetal outcome comprises fetal distress and fetal death, Apgar score, need for oxygen administration, and birth weight as well as admission to neonatal intensive care unit

\section{Material and Methods}

\section{Design}

An exploratory descriptive research design was utilized to fulfill this study.

\section{Setting}

The study was conducted in eclampsia units and labor wards, affiliated to Damanhour Medical National Institute in El-Beheira Governorate.

\section{Subjects}

Pregnant women with pre-eclampsia were selected from previously mentioned setting to carry out this study.

\section{Sampling technique}

Purposive sampling method was used for selected pregnant women using simple random sampling technique after identifying the list of rate per setting.

\section{Sample size}

A sample of 200 pregnant women with preeclampsia are needed to detect a clinically meaningful difference at rate of neonates of preeclampsia who needed intensive care unit $(\mathrm{NICU})=$ $16.5 \%$, at alpha level of 0.05 with power of $80 \%$. They were selected according to the following inclusion criteria: in the third trimester of pregnancy, free of chronic diseases e.g. diabetes, hypertension, diagonsed with mild or severe preeclampsia and willing to participate in the study

\section{Tools of data collection}

Three tools were developed by the researchers to collect data.

Tool I : A structured interview questionnaire was developed based on the current review of literature. It was used by the researchers to collect data about thestudy subjects, it entailed the following parts:

Part (1): Socio- demographic data such as age, level of education, occupation, residence, and family income.

Part (2): Data related to current pregnancy such as parity, antenatal visits (time- frequency) and weeks of gestation.

Part (3): Physical examination measurements to obtain baseline data about blood pressure, height and pre pregnancy weight, weight in kilograms and height 
in centimeters were measured for all women included in the study. Weight was recorded to the nearest 0.5 $\mathrm{kg}$, height was recorded to the nearest $0.1 \mathrm{~cm}$ and body mass index (BMI) was calculated. Then, compared with, the reference value to identify overweight or obesity among women as following:

Less than $18.5 \mathrm{~kg} / \mathrm{cm}^{2}$ (underweight) $\quad 18.5-24.9$

$\mathrm{kg} / \mathrm{cm}^{2}$ (normal weight)

$25.0-29.9 \mathrm{~kg} / \mathrm{cm}^{2}$ (overweight) $\quad 30.0-34.9$

$\mathrm{kg} / \mathrm{cm}^{2}$ (obesity) (WHO, 2011)

Tool II: assessment of women's knowledge regarding pre-eclampsia was developed based on the current review of literature .It comprised of 48 items to assess women's knowledge regarding preeclampsia. It included five main groups of questions. These five main groups of questions entail the following information: definition of pre-eclampsia $(\mathrm{N}=1)$, signs and symptoms $(\mathrm{N}=12)$, risk factors $(\mathrm{N}=17)$, consequences $(\mathrm{N}=12)$, preventive measures of pre-eclampsia $(\mathrm{N}=6)$. Subjects' response to each item was scored as follows: complete answer (3), incomplete answer (2), and don't know (1). The total score ranged from (48-144) the subjects' knowledge was ranked as poor, fair, and good knowledge according to their total scores. The highest score in this system conveys better knowledge.

- Good knowledge for total score 112-144

- Fair knowledge for a total score of 80- $<112$

- Poor knowledge for a total score of $48-<80$

Tool III: Pregnancy outcome assessment checklist was developed based on the current review of literature to collect data about

- Maternal assessment checklist was included onset of labor (spontaneous or induced), presence of maternal distress, time of rupture of membranes, type of labor, duration of the three stages of labor, (first, second and third); occurrence of complications during labor.

- Fetal assessment checklist included: presence of fetal distress, neonates status (alive, stillborn or dead), birth weight, Apgar score at one and five minutes (normal, mild or severe asphyxia) and need for oxygen administration and admission to neonatal intensive care unit.

- Ethical consideration: For each recruited subject the following issues were considered: Securing the subject's informed consent, keeping the subject's privacy, assuring the subjects of their data confidentiality, and the right to withdraw at any time.

Methods

The study was carried out according to the following steps

- An official letter from the Faculty of Nursing, Damanhour University was obtained and forwarded to the responsible authorities of the study setting to take their permission to conduct the study after explaining its purpose.

- Tools of data collection were developed by the researchers after extensive review of relevant and current literature. Tools were checked for content validity by a jury of five experts in the field.

- Tools reliability was tested by Cronbach alpha test. Its result was 0.723 which indicates an accepted reliability of the tool.

- A pilot study was carried out on 20 women excluded from the study to ascertain the clarity and the applicability of the tool as well as to estimate the time needed to it.

- Data were collected through an interview schedule, which was conducted individually and in total privacy. Tool one and two were collected from parturient either during the first stage of labor or during immediate postpartum period after explaining the purpose of study.

- Maternal and fetal assessments (tool three) were used for each study subjects during their four stages of labor to monitor birth outcomes. The average number of interviewee per day was 2-3 depending upon the number of deliveries

- Data were collected over a period of 8 months starting from the beginning of September 2014 till the end of April 2015.

Statistical analysis: data analysis was carried out on window XP using SPSS program version 16. The collected data was categorized, coded, computerized, tabulated and analyzed. Finally, analysis and interpretation of data were conducted using the following statistical measures were used: Descriptive statistical including frequency, distribution, mean, and stander deviation were used to describe different characteristics. Spearman's Rho correlation used to test correlation, between two quantitative variables not normally distributed or dichotomous qualitative variable. 


\section{Results}

Table (1): Distribution of the Study Subjects According to Their Socio-Demographic Data.

\begin{tabular}{|c|c|c|}
\hline Socio-demographic data & $\operatorname{No}(n=200)$ & $\%$ \\
\hline $\begin{array}{l}\text { Age } \\
\begin{array}{l}20- \\
25- \\
30-34\end{array}\end{array}$ & $\begin{array}{l}84 \\
50 \\
66\end{array}$ & $\begin{array}{l}42.0 \\
25.0 \\
33.0\end{array}$ \\
\hline Mean \pm SD & & \\
\hline $\begin{array}{l}\text { Level of education } \\
\text { Illiterate/Read \& write } \\
\text { Basic } \\
\text { Secondary } \\
\text { Higher education } \\
\end{array}$ & $\begin{array}{l}66 \\
44 \\
62 \\
82 \\
\end{array}$ & $\begin{array}{l}33.0 \\
22.0 \\
31.0 \\
14.0 \\
\end{array}$ \\
\hline $\begin{array}{l}\text { Occupation } \\
\text { Housewife } \\
\text { Working }\end{array}$ & $\begin{array}{c}130 \\
70\end{array}$ & $\begin{array}{l}65.0 \\
35.0\end{array}$ \\
\hline $\begin{array}{c}\text { Residence } \\
\text { Rural } \\
\text { Urban }\end{array}$ & $\begin{array}{c}88 \\
112\end{array}$ & $\begin{array}{l}44.0 \\
56.0\end{array}$ \\
\hline $\begin{array}{l}\text { Family income } \\
\text { More than enough } \\
\text { Just enough } \\
\text { Less than enough }\end{array}$ & $\begin{array}{c}30 \\
138 \\
32\end{array}$ & $\begin{array}{l}15.0 \\
69.0 \\
16.0\end{array}$ \\
\hline
\end{tabular}

Table (2): Distribution of the Study Subject According To Their Obstetric Data \& Physical Examination.

\begin{tabular}{|c|c|c|}
\hline Obstetric data & No $(n=200)$ & $\%$ \\
\hline $\begin{array}{ll}\text { Parity } & \\
& \text { Primi } \\
& \text { Multi }\end{array}$ & $\begin{array}{c}132 \\
68\end{array}$ & $\begin{array}{l}66.0 \\
34.0\end{array}$ \\
\hline \multicolumn{3}{|l|}{ Antenatal visits } \\
\hline Yes & 186 & 93.0 \\
\hline No & 14 & 7.0 \\
\hline Time of initial visit & $\mathrm{n}=(186)$ & \\
\hline $1^{\text {st }}$ trimester & 151 & 81.2 \\
\hline $2^{\text {nd }}$ trimester & 31 & 16.6 \\
\hline $3^{\text {rd }}$ trimester & 4 & 2.2 \\
\hline Number of antenatal visits & $\mathrm{n}=(186)$ & \\
\hline$<4$ & 34 & 18.3 \\
\hline$\geq 4$ & 152 & 81.7 \\
\hline $\begin{array}{c}\text { Min-Max } \\
\text { Mean } \pm \text { SD }\end{array}$ & $\begin{array}{c}1-22 \\
6.3 \pm 3.9\end{array}$ & \\
\hline $\begin{array}{c}\text { Week of gestation } \\
<37 \\
\geq 37\end{array}$ & $\begin{array}{c}52 \\
148\end{array}$ & $\begin{array}{l}26.0 \\
74.0\end{array}$ \\
\hline
\end{tabular}




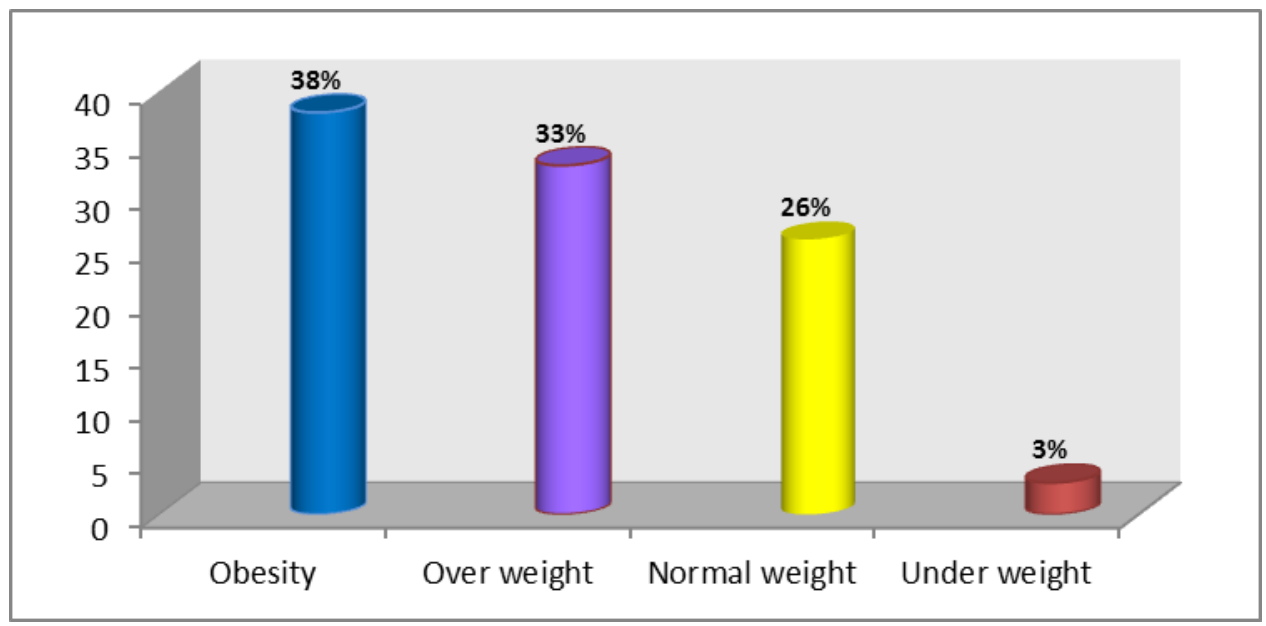

Figure (1): Body Mass Index Of Pre-Eclamptic Pregnant Women.

Table (3): Distribution of the Study Subjects According to Their Labor' Characteristics.

\begin{tabular}{|c|c|c|}
\hline labor' characteristics & No & $\%$ \\
\hline $\begin{array}{l}\text { Onset of labor } \\
\text { Spontaneous } \\
\text { Induced }\end{array}$ & $\begin{array}{c}154 \\
46\end{array}$ & $\begin{array}{l}77.0 \\
23.0\end{array}$ \\
\hline $\begin{array}{c}\text { Maternal distress } \\
\text { Present } \\
\text { Absent }\end{array}$ & $\begin{array}{c}34 \\
166\end{array}$ & $\begin{array}{l}17.0 \\
83.0\end{array}$ \\
\hline $\begin{array}{l}\text { Time of rupture of membranes } \\
\text { Premature } \\
\text { Mature } \\
\end{array}$ & $\begin{array}{c}144 \\
56 \\
\end{array}$ & $\begin{array}{l}72.0 \\
28.0 \\
\end{array}$ \\
\hline $\begin{array}{l}\text { Type of labor } \\
\text { Normal vaginal } \\
\text { Caesarean section }\end{array}$ & $\begin{array}{c}82 \\
118\end{array}$ & $\begin{array}{l}41.0 \\
59.0\end{array}$ \\
\hline $\begin{array}{l}\text { Duration of labor } \\
\text { ( primiparae) } \\
\mathbf{1}^{\text {st }} \text { Stage (hours) } \\
<12 \\
12-16 \\
>16\end{array}$ & $\begin{array}{c}(\mathbf{n}=\mathbf{3 4}) \\
\\
8 \\
20 \\
6\end{array}$ & $\begin{array}{l}23.6 \\
58.8 \\
17.6\end{array}$ \\
\hline $\begin{array}{l}\mathbf{2}^{\text {nd }} \text { Stage (hours) } \\
<1 \\
1-2\end{array}$ & $\begin{array}{c}6 \\
28\end{array}$ & $\begin{array}{l}17.6 \\
82.4\end{array}$ \\
\hline $\begin{array}{c}\mathbf{3}^{\text {rd }} \text { Stage(minutes) } \\
<10 \\
10-20 \\
\end{array}$ & $\begin{array}{c}28 \\
6\end{array}$ & $\begin{array}{l}82.4 \\
17.6\end{array}$ \\
\hline $\begin{array}{l}\text { Duration of labor } \text { (Multiparae) } \\
\mathbf{1}^{\text {st }} \text { Stage (hours) } \\
<6 \\
6-8 \\
>8 \\
\end{array}$ & $\begin{array}{c}(\mathbf{n}=\mathbf{4 8}) \\
4 \\
34 \\
10 \\
\end{array}$ & $\begin{array}{r}8.4 \\
70.8 \\
20.8\end{array}$ \\
\hline $\begin{array}{c}\mathbf{2}^{\text {nd }} \text { Stage (minutes) } \\
10-30 \\
>30\end{array}$ & $\begin{array}{l}36 \\
12\end{array}$ & $\begin{array}{l}75.0 \\
25.0\end{array}$ \\
\hline
\end{tabular}




\begin{tabular}{|c|c|c|}
\hline labor' characteristics & No & \% \\
\hline $\mathbf{3}^{\text {rd }}$ Stage(minutes) & 46 & 95.8 \\
$10-20$ & 2 & 4.2 \\
$>20$ & $\mathrm{~N}=200$ & 24.0 \\
\hline Complications of labor: & 48 & 76.0 \\
Present & 152 & 4.2 \\
Absent & $\mathbf{( n = 4 8 )}$ & 20.8 \\
\hline Type of complications & 4 & 75.0 \\
Genital injury & 20 & 4.2 \\
Prolonged labor & 36 & 4.2 \\
Hemorrhage & 2 & \\
Abruptio placenta & 2 & \\
Cord prolapse & & \\
\hline
\end{tabular}

82 women had normal labor 34 were primi and 48 were multi

\#more than one answer

Table (4): Distribution of Study Subject According to Fetal/ Neonatal Outcome.

\begin{tabular}{||c|c|c|}
\hline Fetal / neonatal outcome & \multicolumn{2}{|c|}{ No } \\
\hline Fetal distress & 64 & 32.0 \\
Present & 136 & 68.0 \\
Absent & & \\
\hline Neonates' status & 174 & 87.0 \\
Live births & 18 & 9.0 \\
Still births & 8 & 4.0 \\
Intrauterine fetal death & $(\mathrm{n}=87)$ & 0.0 \\
Birth weight & 0 & 27.6 \\
1500-2400 & 48 & 72.4 \\
$\geq 2500$ & 126 & 26.5 \\
Normal (7-10) & $(\mathrm{n}=174)$ & 72.3 \\
Mild asphyxia (4-6) & 52 & 1.2 \\
Severe asphyxia (0-3) & 120 & 77.0 \\
Apgar score at 1 minute & 2 & 23.0 \\
Normal (7-10) & $(\mathrm{n}=174)$ & 00.0 \\
Mild asphyxia (4-6) & 134 & 36.8 \\
Severe asphyxia (0-3) & 40 & 63.2 \\
\hline Need for oxygen administration: & 0 & 23.0 \\
Yes & $(\mathrm{n}=174)$ & 77.0 \\
No & 64 & $(\mathrm{n}=174)$ \\
\hline Admission to neonatal intensive unit & 40 & \\
Needed & 134 & \\
Not needed & & \\
\hline
\end{tabular}




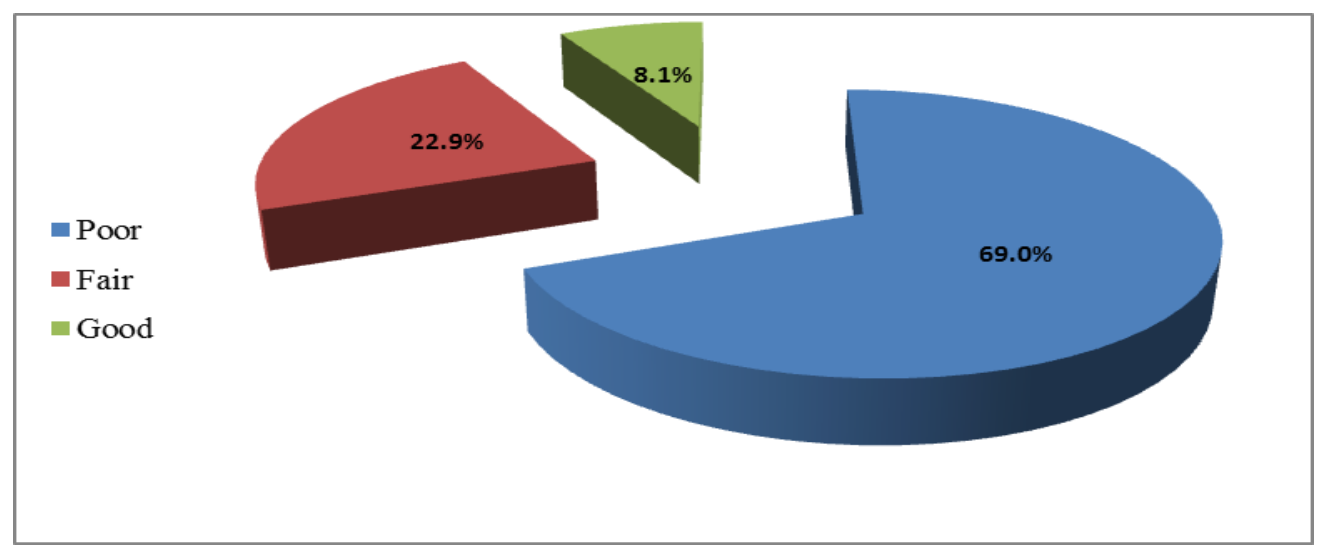

Figure (2) Total Knowledge Score About Pre-Eclampsia Among Studied Women.

Table (5): Correlation ${ }^{\#}$ Between Determinant Factors Of Pre-Eclampsia Among Studied Subjects.

\begin{tabular}{|c|c|c|}
\hline \multirow{2}{*}{ Variables } & \multicolumn{2}{|c|}{ Pre- eclampsia } \\
\hline & $\mathbf{R}$ & $\mathbf{P}$ \\
\hline Age & 0.62 & $0.0001 *$ \\
\hline Education (Not educated/Educated) & 0.39 & $0.0001^{*}$ \\
\hline Occupation (Employed/Not employed) & 0.056 & 0.416 \\
\hline Family income & 0.01 & 0.85 \\
\hline Residence & 0.14 & $0.04 *$ \\
\hline Parity & 0.212 & $0.004 *$ \\
\hline Number of antenatal visit & 0.18 & $0.009 *$ \\
\hline Weeks of gestations & 0.02 & 0.74 \\
\hline Body mass index(BMI) & 0.05 & 0.59 \\
\hline
\end{tabular}

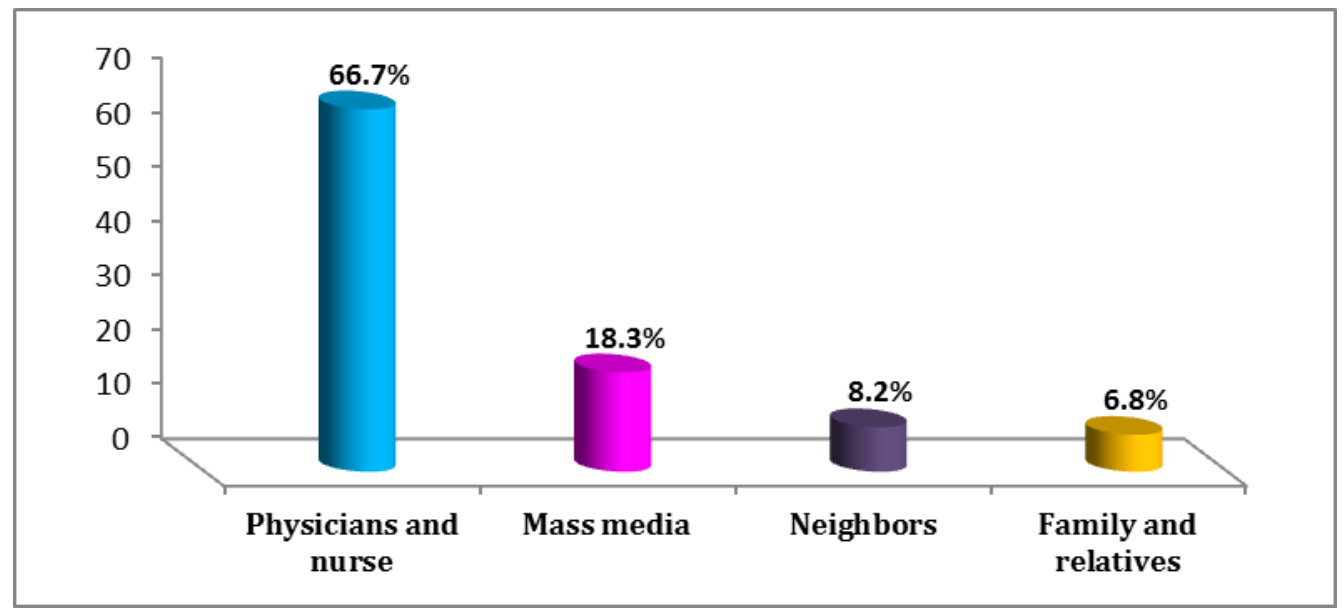

Figure (3): Studied Sample' Sources Of Knowledge About Pre-Eclampsia. 
According to Table (1): $42.0 \%$ of study subjects aged 20 to less than 25 years with mean age $27.48 \pm 8.5$. $31.0 \%$ of them had secondary schools graduates, comparing to only $14.0 \%$ with higher education. As for their occupation, about $65.0 \%$ of them were housewives, and $44.0 \%$ of them were living in rural area. $69.0 \%$ of them had just enough family income.

Table (2): illustrates that $66.0 \%$ of subjects' were primipara. $93.0 \%$ of them received antenatal care. Most of those who received antenatal care $81.2 \%$ had started it during their first trimester, while $2.2 \%$ had started antenatal visits during the third trimester of pregnancy. A good proportion of them $81.7 \%$ received adequate antenatal care ( $\geq 4$ visits) with a mean of $6.3 \pm 3.9$ visits. The subjects' weeks of gestation were less than 37 weeks among $26.0 \%$.

Figure (1): shows $38 \%$ of them were obese and $33 \%$ were overweight. While the pregnant women who were normal body weight and underweight constituted $26 \%$ and $3 \%$ respectively.

Table (3): shows labor characteristics' of study sample. It was obvious that $77.0 \%$ of them had spontaneous onset of labor. In addition, maternal distress didn't occur among $83.0 \%$ of them. Meanwhile, premature rupture of membranes was observed among $72.0 \%$ of them. $59.0 \%$ of them had caesarean section labor. The same table exhibits study subjects according to their duration and complications of labor. Of those normal vaginal labor, 34 women was primipara, duration of the first stage of labor was less than 12 hours among $23.6 \%$ of them. In addition, duration of the second stage was 1-2 hours among $82.4 \%$ of them. Duration of the third stage of labor was 10-20 minutes among 17.6 $\%$ of them.

On the other hands, regarding multipara (48 women), duration of the first stage of labor was 6-8 hours among $70.8 \%$ of the study subjects. Duration of the second stage of labor was 10-30 minutes among $75.0 \%$ of them. In addition, Duration of the third stage of labor was 10-20 minutes among $95.8 \%$ of them. The table also showed that complications of labor were present among $24.0 \%$ of the women; a great percentage $75 \%$ of them had hemorrhage.

Table (4): clarifies fetal/ neonatal outcome among study subjects. Fetal distress was observed among $32.0 \%$ of them. Neonate's status revealed that $87.0 \%$ of them delivered live neonates. In addition, low birth weight (1500-2400 gm) constituted $27.6 \%$ of study subjects. Moreover, Apgar score at one minute was normal (7-10) among $26.5 \%$ of them, mild asphyxia (4-6) was detected among $72.3 \%$ of them. Meanwhile, Apgar score at 5 minutes was found to be normal among $77.0 \%$ of them. However, mild asphyxia was observed among $23.0 \%$ of them.
Furthermore, admission to neonatal intensive care unit and oxygen administration were needed for (23 $\%$ \& $36.8 \%$ ) of study subjects' neonates respectively. Figure (2): demonstrates total score of knowledge about pre-eclampsia among study subjects. It was found that, $69.0 \%$ of study subjects had poor total score, $22.9 \%$ had fair total score. However, good total score was attained by only $8.1 \%$ of them with a mean of $46.6 \pm 21.8$.

Table (5): reveals that, positive significant correlations were observed between pre-eclampsia and age, education, residence, parity as well as number of antenatal visit. Moreover, it was observed that, there were no significant correlations with preeclampsia and occupation, family income, weeks of gestations and body mass index (BMI).

Regarding sources of knowledge of women about pre-eclampsia, Figure (3): illustrates that, $66.7 \%$ of the studied sample obtained their knowledge about of pre-eclampsia from physicians and nurse, while $18.3 \%$ from mass media, in which $8.2 \%$ obtained their knowledge from neighbors and finally $6.8 \%$ of them obtained their knowledge from their family and relatives.

\section{Discussion}

Pre-eclampsia represents an extremely important problem in women's health all over the world. Despite numerous clinical observations and studies, the etiology and exact sequence of pathophysiological events accompanying this specific disorder have still remained unresolved. The most commonly considered concepts, however, include: genetic, endocrine and immunological mechanisms. There is also the potential participation of psychological factors. (Jennifer et al., 2010)

The findings of the present study revealed that more than two-fifths of pre-eclamptic women aged 20 to less than 25 years and it was positive correlation between age and risk of pre-eclampsia.(Table 1) This result is kind of expected where the relevant literatures suggest that young primigravida the increase incidence of PE may be due to poor immune capacity at young age, while increased incidence with increasing age may probably reflect the increasing incidence of essential or latent essential hypertension. This is nearly congruent with (Kuchake et al., 2010) who conducted a study about "Maternal and neonatal outcomes in pre-eclampsia". Their study revealed that there is a J-shaped curve for relationship between maternal age and the incidence of PE with a slightly increased pattern among young pregnant and a markedly increased incidence among the older ones, more than 35 years. So, advanced age is common risk factor for PE. In addition, this finding is similar to 
that of EL-Moselhy et al., results (2011) who study the risk factors and impacts of pre-eclampsia: an epidemiological study among pregnant mothers in Cairo, Egypt. This may be attributed to similarity of population' genetic composition. On the other hand, some studies indicated that there was no significant relationship between the maternal age and preeclampsia Such difference could be due to the specificity of each population and another. Ganesh et al., (2010)

The present study revealed that more than half of preeclamptic women lived in urban communities and it was positive correlation between residence and risk of pre-eclampsia. Table (1) Some potential explanations for these differences are that there is a very high rate of negative smoking particularly among urban women, increase incidence of chronic diseases \& increase stressors among them. An alternative explanation may be related to climatic differences across Egypt regions. Yet, this result is not in congruent with Shawhy \& Sadik results (2011). Who performed study about differential magnitude of high risk pregnancy in rural and urban communities in Egypt, they reported that preeclampsia has remained a significant public health threat in both developed and developing countries contributing to maternal morbidity and mortality globally and with no identifiable residence even rural or urban.

Pre-eclampsia, part of the spectrum of pregnancyinduced hypertension (PIH) is typically a disease of the first pregnancy, with a reduction in incidence among multiparas. Shamsi et al., (2010) the result of the present study showed that, primigravidas accounted for about two thirds in pre-eclampsia women as compared to multigravidas, which accounted for one third. Also, it was positive correlation between parity and risk of pre-eclampsia. Table (2): Similar findings were reported in two studies. The first was carried out by Al-Mulhim et al., (2003) about pre-eclampsia: maternal risk factors and perinatal outcome. The second was carried by Pridjian et al., (2002) about Pre-eclampsia: clinical and pathophysiologic considerations. However, these results are incongruent with study done by Muti et al., (2015) who found that women with high- parity are at an increased risk of developing pre-eclampsia. This discrepancy in the results of this study may be explained by differences in the population characteristic.

The importance of antenatal care has long been universally established and emphasized. Proper antenatal care is widely accepted as one of the most important factors which determine better pregnancy outcomes. (Aksornphusitaphong \& Phupong (2012). The findings of the present study revealed that, more than two- thirds of pre-eclamptic women visited the antenatal clinic more than 4 times and it was positive correlation between antenatal visits and risk of pre-eclampsia. (Table 2) It was positive to find-out that the majority of women attended antenatal clinics in many of the available health settings of the community any way. This may be due to the fact that almost one-third of pre-eclamptic women had secondary schools graduates and had enough family income as well as more than one third were working. Table (1) This was expected, since educated women are more likely to have better access to the community health care and family planning services that help in the prevention, early detection and management of obstetric complications. Moreover, there was positive correlation between level of education and risk of pre-eclampsia, while no correlation regarding family income and occupation. (Table 5) Moghadam et al., (2012) this result is in accordance with literature which emphasizes the importance of education and antenatal visit for pregnant women to avoid or decrease the incidence of complications during pregnancy, labor and postpartum period. Pervin et al., (2012) Moreover, study done by Shweta et al., (2011) on Evidence - Based prenatal care visits revealed that the number of prenatal care visits for pregnant women was approximately nine visits for nulliparous women and seven visits for parous women.

On the contrary with this present study, result the study of Sultana et al., (2013) \& Anthony et al., (2012) The first had studied risk factors for preeclampsia. They had reported that severe preeclampsia was commonly observed in unbooked cases, who received minimal or no antenatal care. The second had investigated the impact of prenatal care on neonatal deaths in the presence and absence of antenatal high-risk conditions.

The result of present study further revealed that no statistically significant correlation was found between pre-eclamptic women and body mass index (BMI). Table (5) This finding is in line with Lou et al., (2008) \& Ziaei et al., (2008) who reported that no statistically significant correlation was found between pre-eclamptic women and body mass index between PE cases and controls.

On the other hand, these results are incongruent with Agudelo's \& Belizan's results (2000) who did a study about risk factors for pre-eclampsia in a large cohort of Latin American and Caribbean women. They concluded that overweight and obesity contribute significantly to pre-eclampsia and prepregnancy and body-mass index (BMI) is associated with increased blood pressure throughout pregnancy. In addition, the current finding doesn't agree with the studies of Jacobs et al., (2007) in South Australia 
which revealed that incidence of both mild and severe hypertensive disorders of pregnancy rises with increasing BMI. It doesn't also match with the study of Bodnar et al., (2007) about "pre-pregnancy body mass index and the occurrence of severe hypertensive disorders of pregnancy" they demonstrate a consistently strong positive association between maternal pre-pregnancy body mass index and the risk of pre-eclampsia. (Barua, 2012)

Onset of labor may occur spontaneously in cases of $\mathrm{PE}$ and eclampsia or it is more likely to be stimulated by artificial induction. Hypertensive pregnant patients have 3-4 times more preterm deliveries than did the normotensive women. (Ye, RW. 2009) In the current study, more than three quarters of women with pre eclampsia had spontaneous onset of labor. (Table 3) Pre-eclampsia considered as major causes of morbidity and mortality both in mother and fetus (Sultana \& Aparna, 2013). The present study revealed that pre-eclampsia was significant association with higher rate of premature rupture of membrane, caesarean births and induced labor, maternal distress. (Table 3) This result is in accordance with Vreeburg et al., (2004) they did study about Hypertension during pregnancy: risk factors for adverse maternal and/or perinatal outcome. They reported that the hypertensive group had high incidence of induced labor and an increased risk for low birth weight. In addition, this result agrees with Kolusari et al., (2008) \& Plunkett et al., (2008), who mentioned that onset of labor may occur spontaneously in cases of PE and eclampsia or it is more likely to be stimulated by artificial induction. Moreover, they further elaborated that adverse pregnancy outcomes associated with pre- eclampsia, such as maternal distress, early rupture of membranes and many complications for mother and infant.

Women with pre-eclampsia have an increased rate of cesarean section consequent upon the high incidence of intrauterine growth restriction, fetal distress and prematurity. ( Polsani et al., 2013) This finding accordance with results of this study in which the almost more than half of pre- eclampsia women delivered by cesarean section. Table (3) This result coincides with the findings of Witlin et al., (2000) who mentioned that operative delivery by cesarean section in pregnancies with pre-eclampsia reduced complications to the fetus as well as the mother. The same result is also supported by Gofton et al., (2001) and Al-Mulhim et al., (2003) works who found that an increase rate of caesarean birth among mothers who were pre-eclamptic and vaginal deliveries were less frequent in women with pre-eclampsia as compared with healthy controls.

Increase rate of caesarean may be result from prolonged labor, where pre-eclampsia had significantly prolonged labor, premature rupture of membrane, In disagreement of this current study, results of study done in Nigeria by Iyoke, et al., (2014) indicated that about one quarter of women delivery by cesarean section. Difference may be due to the variation in approach of management and control of pre-eclampsia. So it was not surprisingly, there are marked complications of labor were presented among $24 \%$ of pre-eclamptic women. These complications include genital injury, prolonged labor, hemorrhage, abruptio placenta, cord prolapsed and retained placenta. (Table 3 )

The neonatal morbidity was more common in preeclampsia. (The American College of Obstetricians \& Gynecologists (ACOG) Committee on Practice Bulletins--Obstetrics 2012) The result of the present study revealed that lower birth weight, and APGAR score associated with pre-eclamptic women. Table (4) This may be resulted from fetal distress which was also higher among the study subjects. Therefore, the need for resuscitation and oxygen administration were higher among them. This finding coincides with the results of at least three other researches. First, Bener (2013) who had studied the impact of socioeconomic, lifestyle habits and obesity in developing of pregnancy induced hypertension. Second, Attiya et al., (2009) who had studied neonatal outcome in pre-eclamptic patient. Third, Masoura et al., (2012) who had investigated the Neonatal outcomes of late preterm deliveries with pre-eclampsia. The first and third studies had reported that Low APGAR score was seen higher in pre-eclamptic group as compared to controls and there was high need for admission to NICU in preeclamptic group compared to controls. The second further elaborated that pre-eclampsia has great implication on adverse neonatal outcome. The various complications seen are low APGAR score, IUD, low birth weight, intrauterine growth restriction and increased need for admission to Neonatal Intensive Care Unit (NICU).

On the other hand, the current finding is incongruent with study of done by Xu Xiong et al., (2002) who had studied impact of pre-eclampsia and gestational hypertension on birth weight by gestational age. They reported that infants born at term to mothers with preeclampsia have similar birth weights, on average, to those of infants born to women who do not experience this condition; however, infants born preterm to mothers with pre-eclampsia weigh significantly less than those born to women with normal blood pressure during pregnancy.

As expected infants of PE women were delivered earlier and, therefore, there was significant difference in birth weight of the neonates of PE patients compared to normal pregnancy $(2.26 \pm 0.91$ vs. 
$3.22 \pm 0.41 \mathrm{Kg}$,). ${ }^{(44)}$ The results of the present study indicated that low birth weight (1500-2400 gm) constituted more than one fourth of pre-eclamptic women. These finding supported by other studies revealed the same results, Barton et al., (2001) observed that the mean birth weight of the neonate was significantly lower in the group with preeclampsia than that of gestational hypertension. Kenny et al., (2014) found that pre-eclampsia was associated with a 5\% reduction in birth weight. In severe pre-eclampsia, the reduction was $12 \%$ and in early onset disease, birth weight was $23 \%$ lower than expected.

The present study revealed that women were more likely to obtain poor total score of knowledge. Figure (2) This finding is expected since women in the present study were more likely to be illiterates or basic education, housewives and from rural areas. They were also had just enough family income. Women with this background are less exposed to biomedical system (they go to the doctor less frequently) although, two thirds of women in the current study mentioned physicians and nurses as the main source of their knowledge regarding preeclampsia. Figure (3) In addition, they had less information about morbid conditions and where to go for treating each. This finding is consistent with the study of Whitney et al., (2012) about factors associated with patient understanding of preeclampsia, where concluded that pregnant patients have a generally poor understanding of preeclampsia.

The current finding also corresponds with the study of Okpomeshine's, (2014) about "knowledge, attitudes, and perceptions of pre-eclampsia among first-generation Nigerian women in the United States ". She reported that the lowest knowledge of preeclampsia was 1.15 times more common $(\mathrm{OR}=1.15$, $95 \%, \mathrm{CI}=0.45-2.98)$ than greater knowledge of preeclampsia.

Pre-eclampsia is a largely preventable condition \& the maternal mortality is decreasing, but the perinatal mortality still remains very high $(7-10 \%)$ even in the developed and developing countries .With the target of the Millennium Development Goals in sight, preeclampsia/eclampsia needs to be identified as a priority area in reducing maternal mortality in developing countries. Since the mainstay of control remains health care based strategies, national governments and supporting agencies should channel efforts at strengthening the maternity and public health systems and improving access to trained health care providers. (Fatemeh, et al., 2010)

\section{Conclusion}

According to the findings of the present study it could be concluded that, age, level of education, residence, parity, and antenatal visits were determinants risk factors of pre-eclampsia in which that was significantly associated with maternal and neonatal morbidities as well as increasing cesarean section, LBW, and birth asphyxia. Need for oxygen administration and admission to neonatal intensive unit.

\section{Recommendations}

Based on the study findings it is recommended that:

- Teaching programs should be conducted by nurses to identify mothers at risk to offer them counseling and refer them to a hospital where pre-eclampsia can be managed. This is expected to reduce the perinatal mortality and morbidity and associated with pre-eclampsia in resource-limited settings.

- Proper antenatal care must be given to all pregnant women for early identification of pregnant women who have a high-risk for severe pre-eclampsia, subsequent monitoring and treatment of pregnancies with pre-eclampsia.

- Measures should be taken to control this deadly condition through behavioral change communication $(\mathrm{BCC})$ regarding antenatal care, danger signs, delivery plan etc, involving both public and private sectors.

- Hence creating community awareness along with an improvement in the antenatal care and neonatal facilities will go a long way in reducing the incidence of pre-eclampsia and eclampsia.

- Further in depth researches are needed in different areas and on large scale in Egypt for full understanding of pre-eclampsia.

\section{Acknowledgement}

The authors thank the Directories of Damanhur Medical National Institute in El-Beheira governorate and their special gratitude goes to the nursing staff for their assistance and valuable information. A word of thanks goes also to the pregnant women who gave their valuable time and participated in the study.

\section{References}

1. Aksornphusitaphong, A., \& Phupong, V., (2012): Risk factors of early and late onset preeclampsia, J Obstet Gynaecol Res doi, vol. (10), No. (1447).

2. Alam, N., (2010): Obstetrics and gynecology, Philadelphia: Elsevier, 94-8.

3. Al-Mulhim, A., Abu-Heija, A., Al-Jamma, F., \& El-Harith, H., (2003): Pre-eclampsia: maternal risk factors and perinatal outcome, 
Fetal Diagn Ther, vol.(18), Pp. 275-80.

4. American College of Obstetricians \& Gynecologists (ACOG) Committee on Practice Bulletins-Obstetrics, (2012): ACOG practice bulletin. Diagnosis and management of pre-eclampsia and eclampsia. Obstet Gynecology, vol. (99), No. (33). Pp. 159-67.

5. Anthony, M., Vintzileos, C., \& Ananth, V., John, C., William, E., \& Robert, A., (2012): The impact of prenatal care on neonatal deaths in the presence and absence of antenatal high-risk conditions,American Journal of Obstetrics and Gynecology, vol.(186), No. (5). Pp. 1011-16.

6. Attiya, A., Taj, M., Shaheryar, A., \& Sadia, H., (2009): Neonatal outcome in pre-eclamptic patients, J Ayub Med Coll Abbottabad Pakistan, vol. (21), No. (2). Pp. 1-7.

7. Baker A., Haeri, S., Camargo C., Jr. Espinola, J., \& Stuebe, A., (2010): A nested case-control study of midgestation vitamin D deficiency and risk of severe preeclampsia. J. Clin. Endocrinol. Metab, vol. (95),No. (11)Pp. 5105-9.

8. Barton, J., O'Brien, J., Bergauer, N., Jacques, DLDL. \& Sibai, B., (2001): Mild gestational hypertension remote from term: progression and outcome, Am J Obstet Gynecol, vol. (184), No. (5). Pp. 979-83.

9. Barua, R., (2012): Macroscopic and microscopic changes in human placenta in gestational diabetes and eclampsia, Unpublished Master thesis, Faculty of Medicine, Dhaka, BSMMU University.

10. Bodnar, L., Catov, J., Klebanoff, M., Ness, R., \& Roberts, J., (2007): Pre-pregnancy body mass index and the occurrence of severe hypertensive disorders of pregnancy, Epidemiology, vol.(18), No. (2). Pp. 234-9.

11. Bener, A., \& Saleh, N., (2013): The impact of socioeconomic, lifestyle habits and obesity in developing of pregnancy induced hypertension in fast growing country: Global comparisons.Clin Exp Obstet Gynaecol vol. (40) No.(1):Pp. 52-7.

12. Casey, E., Copen, D., Marie, E., Sharon, K., \& Williams, S., (2015): Inter pregnancy Intervals in the United States: Data From the Birth Certificate and the National Survey of Family Growth, National Vital Statistics Reports, vol.(64),No.(3).Pp.1-11.

13. Costa, C., (2009): The global impact of preeclampsia and eclampsia. Semin Perinatol, vol. (33), Pp. 130-7.

14. Costa, C., \& Howat, P., (2010): Clinical cases in obstetrics, gynecology and women's health Obstetrics, $23^{\text {th }}$ edition, chapter 4, New York: The McGraw-Hill, 706-26. Retrieved at May 2010.
15. Conde-Agudelo, A., \& Belizan, J., (2000): Risk factors for pre-eclampsia in a large cohort of Latin American and Caribbean women, BJOG, vol. (107), Pp. 75-83.

16. Dekker, G., (2014): Management of preeclampsia, An International Journal of Women's Cardiovascular Health, vol. (4), No. (3). Pp. 246-9. Online: www.elsevier.com/locate/preghy.

17. EL-Moselhy, E., Khalifa1, H., Amer1, S., Mohammad, K., \& Abd El-Aal, H., (2011): Risk Factors and Impacts of Pre-eclampsia: An Epidemiological Study among Pregnant Mothers in Cairo, Egypt, Journal of American Science, vol. (7), No. (5). Pp. 311-23.

18. Fatemeh, T., Marziyeh, G., Nayereh, G., Anahita, \& G., Samira, T., (2010): Maternal and perinatal outcome in nulliparous women complicated with pregnancy hypertension, J Pak Med Assoc, vol. (60), No. (9). Pp. 707-10.

19. Ganesh, K., Unnikrishnan, B., Nagaraj, K., \& Jayaram, S., (2010): Determinants of preeclampsia: a case-control study in a district hospital in South India,Indian J Community Med, vol.(35), Pp. 502-505.

20. Gofton, E., Capewell, V., Natale, R., \& Gratton, R., (2001): Obstetric intervention rates and maternal and neonatal outcomes of women with gestational hypertension, Am J Obstet Gynecol, vol. (185), Pp. 798-803.

21. Iyoke, C., Ugwu, G., Ezugwu, F., Lawani, O., \& Onah, H., (2014): Risks associated with subsequent pregnancy after one caesarean section: A prospective cohort study in a Nigerian obstetric population, Nigerian Journal of Clinical Practic, vol.(17), No. (4). Pp. 442-48.

22. Jacobs, D., Vreeburg, S., Dekker, G., Heard, A., Priest, K., \& Chan, A., (2007): Risk factors for hypertension during pregnancy in South Australia, Aust N Z J Obstet Gynaecol, vol. (43), Pp. 421-8.

23. Jennifer, L., Guo, Y., Fan, M., \& Gavin, A., (2010): Psychosocial stress during pregnancy, American journal of obstetrics and gynecology, vol. (202), No. (1). Pp. 61-70.

24. Kate, E., \& Andrew, H., (2015): Recent advances in the diagnosis and management of pre-eclampsia., F1000Prime Rep, vol. (7), No. (24).

Online http://f1000.com/prime/reports/m/7/24.

25. Kenny, L., Black, M., \& Poston, L., (2014): Early pregnancy prediction of preeclampsia in nulliparous women, combining clinical risk and biomarkers: the Screening for Pregnancy Endpoints SCOPE) international cohort study. Hypertension. vol. (64), No. (3). Pp. 64452. 
26. Kolusari, A., Kuroglu, M., Yildizhan, R., Adali, E., Edirne, T., Cebi, A., Demir, H., \& Yoruk, I., (2008): Catalase activity, serum trace element and heavy metal concentrations, and vitamin A, D and E levels in pre-eclampsia .J internat Med Res, vol.(36), Pp. 1335-41.

27. Kuchake, V., Kolhe, S., Dighore, P., \& Patil, S., (2010): Maternal \& neonatal outcomes in preeclampsia syndrome, IJPSR, vol. (1), No. (11). Pp. 74-82.

28. Laura, A., Magee, A., Anouk Pels, B., Michael Helewa, C., \& Evelyne Rey, D., (2014): Diagnosis, evaluation, and management of the hypertensive disorders of pregnancy, Pregnancy Hypertension: An International Journal of Women's Cardiovascular Health, vol. (4), Pp. 105-45.

Online: www.elsevier.com/locate/preghy.

29. Lou, S., Amirabi, A., Yazidian, A., \& Pashhapour, S., (2008): Evaluation of serum calcium, magnesium, copper and Zinc levels in women with pre-eclampsia, IJMS, vol. (33), No. (4). Pp. 231-4.

30. Masoura, S., Kalogiannidis, I., MargioulaSiarkou, C., Diamanti, E., Papouli, M., Drossou-Agakidou, V., Prapas, N., \& Agorastos, T., (2012): Neonatal outcomes of late preterm deliveries with pre- eclampsia, Minerva Ginecol, vol.(64), No. (2). Pp. 109-15.

31. Moghadam, D., Khosravi, A., \& Sayehmiri, K., (2012): Predictive factors for pre-eclampsia in pregnant women: an unvariate and multivariate logistic regression analysis.ABP, vol. (343), No. (59). Pp. 1-5. Online : www.actabp.pl

32. Muti, M., Shimanga, M., Notion, G., Bangure, D., \& Chonzi, P., (2015): Prevalence of pregnancy induced hypertension and pregnancy outcomes among women seeking maternity services in Harare, Zimbabwe. BMC Cardiovascular Disorders, vol.(15), No. (111).

33. Namitha, J., Sudha, A., \& Sangeeta, K., (2010): Assess the Knowledge Regarding Preeclampsia and Its Self-care Measures among Antenatal Women Attending Antenatal Outpatient Department of KLES Dr Prabhakar Kore Hospital, Belgaum. South Asian Federation of Obstetrics and Gynecology, vol. (2), No. (2). Pp. 157-162.

34. Okpomeshine, C., (2014): Knowledge, Attitudes, and Perceptions of Pre-eclampsia among First-Generation Nigerian Women in the United States, vol.(22), Pp. 134-144.

35. Pervin, J., Moran, A., Rahman, M., Razzaque, A., Sibley, L., Streatfield, P., Reichenbach, L., Koblinsky, M., Hruschka, D., \& Rahman,
A., (2012): Association of antenatal care with facility delivery and perinatal survival-a population-based study in Bangladesh, BMC, Pregnancy Childbirth, vol. (12), No. (111).

36. Plunkett, J., Borecki, I., Morgan, T., Stamilio, D., \& Muglia, L., (2008): Population-based estimate of sibling risk for preterm birth, preterm premature rupture of membranes, placental abruption and pre-eclampsia. BMC Genet, vol. (9), No. (44).

37. Polsani, S., Phipps, E., Jim, B., (2013): Emerging new biomarkers of pre-eclampsia, Adv Chronic Kidney Dis, vol. (20), Pp. 271-79.

38. Pridjian, G., \& Puschett, J., (2002):Preeclampsia. Part 1: clinical and pathophysiologic considerations, Obstet Gynecol Surv, vol. (57), Pp. 598-618.

39. Rathore, R., Butt, N., Iqbal, A., \& Khan, M., (2010): Complications and outcome of patients of pre-eclampsia and eclampsia, ANNALS JanMar, vol. (16), No. (1)Pp. 17-19.

40. Shamsi, U., Hatcher, J., Zuberi, N., Qadri, Z., \& Saleem, S., (2011): Multicenter matched case control study of risk factors for pre-eclampsia in healthy women in Pakistan, BMC Women's Health, vol. (10), No. (14). Pp. 128-35.

41. Shawhy, R., \& Sadik, D., (2011): Congenital malformations prevalent among Egyptian children and associated risk factors, Egyptian Journal of Medical Human Genetics, vol. (12), No, (1) Pp. 69-78.

42. Shweta, A., \& Kirshnan A., (2011): Perinatal Outcome in Growth Retarted Babies Born to Normotensive \& Hypertensive Mothers: A Prospective Study. Available at http://www.pjsr.org/Jan12_pdf/5 (Accessed 19/11/2014)

43. Sudha, R., Ratna, P., \& Puri, R., (2009): Stress, coping strategies, quality of life and lived experiences of women with pregnancy induced hypertension, South Asian federation of obstetrics and gynecology, vol.(1), No. (1). Pp. 65-8.

44. Sultana, A., \& Aparna, J., (2013): Risk factors for pre-eclampsia and its perinatal outcome, Annals of Biological Research, vol. (4), No. (10). Pp. 1-5. online at www.scholarsresearchlibrary.com.

45. Vreeburg, S., Jacobs, D., Dekker, G., Heard, A., Priest, K., \& Chan, A., (2004): Hypertension during pregnancy in South Australia, part 2: risk factors for adverse maternal and/or perinatal outcome-results of multivariable analysis. N Z J Obstet Gynaecol , vol.(44), Pp. 410-8. 
46. Whitney, B., Michael, W., Stacy Cooper, B., Anjali, U., Pandit Katherine, R., Rina, M., \& William, G., (2012): Factors Associated with Patient Understanding of Pre-eclampsia Hypertens Pregnancy, vol. (31), No. (3). Pp. 341-9.

47. World Health Organization, (2011): Make every mother and child count, the world health report 2011, World Health Organization, Geneva, Switzerland, 2011.

48. World Health Organization, (2011): Global Database on Body Mass Index. Online ww.apps.who.int/bmi/ index.jsp.

49. Witlin, A., Saade, G., Mattar, F., \& Sibai, B., (2000): Predictors of neonatal outcome in women with severe pre-eclampsia or eclampsia between 24 and 33 weeks' gestation, Am J Obstet Gynecol , ol.(182), Pp. 607-11.

50. Xu, Xiong, (2002): Impact of pre-eclampsia and gestational hypertension on birth weight by gestational age, American Journal of Epidemiology, vol. (155), No. (3). Pp. 203-209.

51. Ye, R., Liu, Y., Ma, R., Ren, A., \&000000000...... Liu, J., (2009): Association between pregnancy-induced hypertension, cesarean delivery and perinatal mortality: a prospective study. vol. (30), No. (9). Pp.891-4. Available

http://www.ncbi.nlm.nih.gov/pubmed/20193221 [accessed 28/05/2012]

52. Ziaei, S., Ranjkesh, F., \& Faghihzadeh, S., (2008): Evaluation of 24-hour copper in preeclamptic vs. normotensive pregnant and nonpregnant women, Intrnat J Fert Ster, vol. (2), No. (1). Pp. 9-12. 